\title{
Resolving issues with environmental impact assessment of marine renewable energy installations
}

\author{
Ilya M. D. Maclean ${ }^{*}$, Richard Inger ${ }^{1}$, David Benson ${ }^{1}$, Cormac G. Booth ${ }^{2}$, Clare B. Embling ${ }^{3,4}$, \\ W. James Grecian ${ }^{5}$, Johanna J. Heymans ${ }^{6}$, Kate E. Plummer ${ }^{3,7}$, Michael Shackshaft $^{8}$, \\ Carol E. Sparling ${ }^{2}$, Ben Wilson ${ }^{6}$, Lucy J. Wright ${ }^{7}$, Gareth Bradbury ${ }^{8}$, Nadja Christen $^{3}$, \\ Brendan J. Godley ${ }^{3}$, Angus C. Jackson ${ }^{9}$, Aly McCluskie ${ }^{10}$, Rachel Nicholls-Lee ${ }^{11}$ and Stuart Bearhop ${ }^{3}$ \\ Environment and Sustainability Institute, University of Exeter, Penryn, UK \\ 2 SMRU Marine Ltd., New Technology Centre, University of St. Andrews, St. Andrews, UK \\ ${ }^{3}$ Centre for Ecology and Evolution, University of Exeter, Penryn, UK \\ ${ }^{4}$ Marine Biology and Ecology Research Centre, Marine Institute, Plymouth University, Plymouth, UK \\ ${ }^{5}$ Institute of Biodiversity, Animal Health and Comparative Medicine, College of Medical, Veterinary and Life Sciences, University of Glasgow, Glasgow, UK \\ ${ }^{6}$ The Scottish Association for Marine Science, Scottish Marine Institute, Oban, UK \\ ${ }^{7}$ British Trust for Ornithology, Thetford, UK \\ ${ }^{8}$ Wildfowl \& Wetlands Trust (Consulting) Ltd., Slimbridge, UK \\ ${ }^{9}$ Environmental Research Institute, North Highland College, University of the Highlands and Islands, Thurso, UK \\ 10 The Royal Society for the Protection of Birds, Centre for Conservation Science, RSPB, Edinburgh, UK \\ $"$ Mojo Maritime Ltd., Falmouth, UK
}

\section{Edited by:}

Robin Margaret Warner, University of Wollongong, Australia

Reviewed by:

Timo M. Koivurova, University of Lapland, Finland

Anne Marie Geraldine O'Hagan, University College Cork, Ireland

${ }^{*}$ Correspondence:

Ilya M. D. Maclean, Environment and Sustainability Institute, College of Life and Environmental Sciences, University of Exeter, Penryn

Campus, Penryn TR10 9FE, UK e-mail:i.m.d.maclean@exeter.ac.uk
Growing concerns about climate change and energy security have fueled a rapid increase in the development of marine renewable energy installations (MREIs). The potential ecological consequences of increased use of these devices emphasizes the need for high quality environmental impact assessment (EIA). We demonstrate that these processes are hampered severely, primarily because ambiguities in the legislation and lack of clear implementation guidance are such that they do not ensure robust assessment of the significance of impacts and cumulative effects. We highlight why the regulatory framework leads to conceptual ambiguities and propose changes which, for the most part, do not require major adjustments to standard practice. We emphasize the importance of determining the degree of confidence in impacts to permit the likelihood as well as magnitude of impacts to be quantified and propose ways in which assessment of population-level impacts could be incorporated into the EIA process. Overall, however, we argue that, instead of trying to ascertain which particular developments are responsible for tipping an already heavily degraded marine environment into an undesirable state, emphasis should be placed on better strategic assessment.

Keywords: ecological impact assessment, environmental impacts, marine biodiversity, marine protected areas, offshore wind, wind farm, wind power, United Kingdom

\section{INTRODUCTION}

Concerns about climate change have driven a shift in energy production to renewable sources. Onshore renewable energy devices often compete with other land uses and cause aesthetic and environmental concerns (Devine-Wright, 2005). This, coupled with the increased ability to harness energy from offshore wind, wave and tidal sites, is fueling the rapid development of marine renewable energy installations (MREIs). This development is operating against a backdrop of increased concern for the plight of the marine environment (e.g., Halpern et al., 2008). MREIs have the potential to exasperate deleterious impacts on the environment but can also provide significant benefits. Although habitat loss, collision with energy devices, noise and other disturbance can all have adverse effects, the creation of artificial habitat and fisheries exclusion zones around MREIs could benefit many species (Inger et al., 2009).

This contradictory situation places a premium on effective environmental assessment and monitoring of impacts.
Assessment should, in theory, help guide decisions as to where renewable devices should be best placed and under what circumstances consent for building or operating these devices should be refused. Effective post consent monitoring should provide an important feedback step to decrease uncertainty for future predictions and consent decisions as well as allowing adaptive management of any impacts that may arise. The need to carry out effective environmental impact assessments (EIAs) is particularly pertinent in the UK marine environment. Some of the world's largest developments are proposed for the UK territorial seas and continental shelf, which hosts internationally important populations of several marine vertebrates (Mitchell et al., 2004), but the impact of human activities there is among the highest in the world (Halpern et al., 2008).

In this paper, we argue that the EIA process is hampered by ambiguities in the legislation, and lack of clear procedural guidance with regards to how the legislation should be implemented. Consequently, the process of determining whether the impact 
of an MREI is significant is, at best, inconsistent and, at worst, highly misleading. Here, after giving an overview of the EIA process, we discuss some of the core conceptual issues underpinning EIA and demonstrate some of the problematic assumptions associated with these. A number of ways in which these problems could be overcome without radically overhauling the current EIA process are then suggested. Overall, however, we propose that focusing more resource and effort on Strategic Environmental Assessment (SEA), and effective negotiations and collaborations between regulators, statutory advisory bodies and developers, is likely to be the most effective way to meet the UK's renewable energy demands while also safeguarding the seas.

\section{THE EIA PROCESS}

While the ways in which EIAs are conducted differ by country, in the UK, this process derives from European Union (EU) law. The EU Directive (2014/52/EU), amending Directive 97/11/EC on The Assessment of the Effects of Certain Public and Private Projects on the Environment states that "Member States shall adopt all measures necessary to ensure that, before development consent is given, projects likely to have significant effects on the environment by virtue, inter alia, of their nature, size or location are made subject to a requirement for development consent and an assessment with regard to their effects on the environment." Assessment of MREI impacts in England and Wales is also governed by the Marine Works (EIA) (Amendment) Regulations 2011, which refer to and apply to marine licenses under the Marine and Coastal Access Act 2009. In Scotland, applications for MREI projects are governed by marine licensing under part 4 of the Marine (Scotland) Act 2010.

Typically, there are several stages to an EIA. Screening is undertaken to determine whether or not an EIA is required. If needed, scoping is carried-out to determine the content and extent of the matters that should be covered in the environmental information submitted to a competent authority. The EIA itself is an analysis of the potential significant environmental effects associated with major development proposals and the communication of this information to decision-makers and the broader public (Wood, 2008). The results of these analyses are reported in the form of an Environmental Statement and the assessment is then performed by the Competent Authority. With regards to MREIs, there is typically a need to monitor any impacts that were assessed as either potentially of moderate significance or around which there was a reasonable degree of uncertainty, particularly where there are considerations with regards to Habitats Directive legislation. This leads to the design and implementation of a monitoring programme with the ultimate objective of assessing the significance of impacts during installation, operation, and decommissioning. Outcomes of the EIA process are usually attached to the consent as specific terms and conditions to which the developer must comply.

\section{THE ISSUES}

\section{PREDICTING A SIGNIFICANT IMPACT}

Before discussing the issue in detail, it is worth outlining the different ways in which the term "significance" is used. In statistical contexts it means having a low probability of obtaining a test statistic at least as extreme as the one that was actually observed solely by chance, assuming that the null hypothesis is true. However, in the context of EIAs, the term "significant" has a different meaning and this evolves through the EIA process. As an EIA progresses from project screening to scoping and through to impact prediction, monitoring and mitigation, the detail and availability of environmental information increases and there are changes in the decision-processes surrounding significance and the nature of related uncertainties (Wood, 2008). For the sake of clarity, it is also worth noting that the meanings are different in the context of EIA Regulations and the Habitats Regulations. Significance in the context of the Habitats Directive $(92 / 43 / \mathrm{EEC})$ is used as a coarse filter to establish the overall scale of the impact and whether a possible pathway for an effect can be identified. Where the possibility of a likely significant effect on a Natura 2000 site is identified, an "appropriate assessment" is required to determine whether or not there will be an adverse effect on the integrity of a European site. Significance in the context of the EIA Regulations is used to describe the relative importance of impacts on any feature of importance, regardless of the application of the Habitats Directive, although the amended Directive (2014/52/EU) calls for coordinated and/or joint procedures fulfilling the requirements of both directives. Further, the European Court of Justice typically uses purposive approach to statutory interpretation, such that one would typically seek to look for the purpose of the legislation before interpreting the words.

Globally, the most widely used method by practitioners to assess the degree of significance of a predicted impact is through the application of the Leopold matrix (Leopold, 1971) or some adaption thereof. A matrix with columns representing the various activities of a project and rows representing the various environmental factors to be considered is constructed. Each combination is scored to indicate the magnitude and importance of the impact of each activity on each environmental factor and the two in combination used to assess the significance of the impact. In the UK, methods typically deviate somewhat from the standard Leopold approach, but the logic is broadly comparable. For example, it may entail cross-tabulating the sensitivity of species with the magnitude of impacts to determine the overall significance of an impact (Percival et al., 1999). The sensitivities are either assessed solely on the basis of conservation importance, or in combination with measures of species sensitivities to particular impacts (Maclean et al., 2009). Other guidelines propose different approaches. For example, the IEEM guidelines (IEEM, 2010) propose that where no conservation designations apply, significance can be evaluated by using one aspect of the magnitude of the impact, for example "the proportional extent of an affected site."

The subjectivity of this guidance, while offering advantages in terms of designing bespoke assessment methods, leaves room for inconsistency. The lack of a single standard protocol for (a) determining what is meant by a significant impact, and (b) determining whether or not an impact is likely to be significant, means that the term "significant" is often interpreted in different ways (Lawrence, 2007; Wood, 2008). While conceptual malleability offers advantages in terms of making pragmatic and sensible decisions in relation to a wide spectrum of potential impacts 
on different components of biodiversity, it also substantially increases variation in practice (Lawrence, 2007).

\section{MONITORING TO DETECT A SIGNIFICANT IMPACT}

When monitoring impacts, a statistical interpretation of the meaning of significance is usually used. Therefore, one of the difficulties associated with determining significance is the degree of natural variability in abundance, behavior, and/or distribution of many marine organisms. At any given location, numbers can vary substantially over time or may already be experiencing a trend (Taylor et al., 2006). However, during the relatively short time frame through which monitoring is carried out, it is often difficult to distinguish any impact from background natural variability (e.g., Grecian et al., 2010; Macleod et al., 2011; Maclean et al., 2013). Unfortunately, there is frequent misinterpretation of monitoring results in impact assessments and it is often assumed that, because no impact could be detected, no impact is occurring (Maclean et al., 2009). However, these are not the same thing; a poorly designed study, or one with lower survey effort, stands a lower likelihood of detecting an impact. While power analysis would enable the likelihood of being able to detect an impact for any given survey effort to be determined, this tool is rarely deployed (Grecian et al., 2010).

\section{DEALING WITH UNCERTAINTY}

It is widely recognized that there is uncertainty as to whether an impact is significant and while a precautionary approach is usually advocated (SNH, 2013), it is important to note that existing approaches used to assess significance do not explicitly quantify both the magnitude and likelihood of an impact, which are ultimately the measures required. When performing statistical tests to detect impacts, significance refers to the probability of observing an effect by chance, but the magnitude of an impact is not quantified. Moreover, because the null hypothesis can never be proven, all impacts should always be deemed significant if the precautionary principle is adopted sensu stricto. In the context of predicting significance during EIAs, significance is a measure of the magnitude of the impact, weighted by the importance of that impact or sensitivity of a species or habitat. However, the likelihood of impacts is not explicitly quantified.

\section{Population-level impacts}

Underpinning the need for an EIA is a concern that a particular development may have an adverse effect on the environment. The impact of MREIs on a population is therefore more relevant than the impact on individuals. The choice of metric for which significance is assessed is thus important. For example, small scale but statistically significant changes in the distribution of an organism (e.g., Keenan et al., 2011) are unlikely to have significant longterm effects on populations. Often, the metric used is proportion of a regional or global population (Percival et al., 1999). Typically however, short-lived species tend to be highly fecund. Where their demographic rates are governed by density-dependence, it is more likely that the population can replace lost individuals. Long-lived species, which raise few young during the course of their lifetime, may thus be particularly sensitive to MREI impacts on mortality and reproduction (Fox et al., 2006). As populationlevel impacts also depend on population size, species with small populations may also be particularly vulnerable. Assessment of effects on a population requires detailed demographic modeling and knowledge of demographic parameters, but such approaches are rarely conducted as part of individual EIAs.

\section{CUMULATIVE IMPACTS}

In the European Union, the assessment of cumulative impacts (CIA) has been required since the EC Directive (85/337/EEC) on EIAs was issued. "Cumulative impacts," according to European Commission (EC) guidelines, should mean "impacts that result from incremental changes caused by other past, present, or reasonably foreseeable actions together with the project." This is a key issue in the context of MREIs, many of which may not have a major impact on the environment individually, but could lead to serious adverse effects when considered as part of incremental changes caused by numerous developments. While recent guidance (King et al., 2009; Broderick et al., 2013) has improved the quality of CIA, there are still a number of key conceptual issues that hamper rigorous assessment.

Foremost amongst these is the ambiguity surrounding the time period over which the benchmark or baseline conditions should be assessed. The concept of a baseline against which to compare predictions of the cumulative effects of proposed actions and reasonable alternatives is critical to the CIA process (Maclean and Rehfisch, 2008; King et al., 2009). However, impacts in the marine environment are continual and on-going. Setting the baseline as the period immediately prior to a development would not capture the cumulative impacts of a series of sequential developments. By contrast, setting the baseline at some arbitrary fixed period runs the risk that almost all projects would be deemed to contribute to significant cumulative impacts due to on-going degradation of the marine environment. In part for this reason, the ways in which cumulative impacts have been interpreted during the EIA process vary substantially in different environmental statements (Maclean et al., 2009). In addition the uncertainties inherent in individual project level assessments are multiplied when multiple projects are considered, often leading to a large degree of uncertainty and over-simplified CIA outputs.

\section{POTENTIAL SOLUTIONS}

While we make a case for the need to change in the way in which marine EIAs are conducted, we acknowledge that there are major barriers which inhibit changes in policy and practice (Kuhn, 1970). Consequently, we present recommendations and potential solutions to each of the major problems outlined above which, for the most part, do not require major adjustments to standard practice. However, these recommendations should be viewed as an interim measure. Overall, a more systematic and strategic approach is needed.

\section{THE SIGNIFICANCE OF IMPACTS AND UNCERTAINTY}

The key problem associated with predicting the significance of impacts is the inconsistency in approaches used. Almost certainly this stems from a paucity of clear guidance with regards to how legislation should be interpreted and implemented, although there is also a need for regulators to demand high quality assessment. Broadly, we recommend the matrix approach (e.g., Percival 
et al., 1999), as greater ambiguity is likely to lead to inadequate assessment (Maclean et al., 2009; Masden et al., 2010) and this approach is already widely used. In so doing, we also recommend that quantitative frameworks for assessment are further developed, as this will allow repeatable, objective assessments of all components in the assessment and facilitate the explicit assessment of uncertainty. When monitoring impacts, we recommend the use of power analyses to determine the likelihood of being able to detect an effect given natural variability in the data.

Irrespective of whether impacts are predicted or monitored, the likelihood as well as the magnitude of the impact should be considered to account for uncertainty. Consequently, we propose that the degree of confidence in impacts should always be assessed by generators of the EIA information and some upper-bound (e.g., 80\%; Akçakaya et al., 2000) confidence level should be considered when making decisions about the significance of impact. Where possible, confidence intervals should be calculated, but in some instances it may be necessary to incorporate expert judgment. Using this principle, an EIA may conclude that a particular effect may fall within a fairly wide range, which is consistent with European Directives to consider a cautious "worst case" approach.

\section{ASSESSING POPULATION-LEVEL IMPACTS}

While detailed demographic modeling would permit better understanding of impacts on populations, in many circumstances, sufficient resources to undertake such modeling are unlikely to be available for individual EIAs. As an interim measure, issues associated with determining population-level impacts could be addressed using two approaches. First, by incorporating measures of how likely populations are to be vulnerable to impacts into the scoring of species sensitivities rather than in assessment of the magnitude of impacts. For seabirds, there are already established sensitivity indices for a variety of MREIs, which account for approximate population level impacts by using adult survival rates as one of the factors determining sensitivity scores (Garthe and Hüppop, 2004; Furness et al., 2012, 2013). Similar indices are being developed for marine mammals (Lusseau et al., 2012), and the likely sensitivities of numerous coastal marine species to a variety of impacts has also been quantified (Tyler-Walters et al., 2001). Second, by developing general frameworks for population modeling and using a distribution of expert's judgments where empirical data on how a disturbance impacts species vital rates are unavailable (Harwood et al., 2014).

\section{THE NEED FOR A STRATEGIC APPROACH}

While the development of guidance and a conceptual framework for cumulative impact assessment (King et al., 2009; Masden et al., 2010) is a step forward, any approach is destined to give meaningless results without clear guidance and advice on the appropriate baselines against which to assess impacts. Much greater emphasis needs to be given to impacts, particularly cumulative impacts during SEA, already enshrined within EU legislation as part of the European SEA Directive (2001/42/EC) and within American legislation as part of the National Environmental Policy Act (NEPA). Instead of trying to ascertain which particular developments are responsible for tipping an already heavily degraded marine environment into an undesirable state, emphasis should be placed on minimizing the conflict between marine biodiversity and MREIs and maximizing their potential to have positive effects. If current practice were altered to place greater emphasis on data collection during SEA, this approach could also offer advantages in terms of more effective pooling of data, more efficient data acquisition and more coordinated efforts to address key knowledge gaps (e.g., Greaves et al., 2011). Although formally implementing these approaches remains a challenge, doing so could also act as a catalyst for cross-cutting research that provides the information needed to support effective impact assessment. Concurrently it would provide opportunities for more transparent negotiations between regulators and developers and would go a long way to optimizing the trade-off between renewable energy delivery and environmental damage.

\section{CONCLUDING REMARKS}

As the world faces the twin challenges of mitigating climate change and ensuring energy security, MREIs are an important means of generating low carbon energy. It is therefore not only timely but a necessity that their potential impacts on the marine environment are understood. Given the degraded nature of marine environments, decisions about how best to minimize environmental impacts while promoting energy security will become increasingly pertinent. We highlight some of the fundamental issues associated with predicting and detecting their impact and present interim solutions to these problems. Overall, however, we believe that, a paradigm shift toward strategic assessment and systematic planning is needed if the potential conflict between MREIs and marine biodiversity are to be minimized.

\section{ACKNOWLEDGMENT}

This manuscript resulted from discussions held during a workshop on tidal energy impacts funded by the Technology Strategy Board.

\section{REFERENCES}

Akçakaya, H. R., Ferson, S., Burgman, M. A., Keith, D. A., Mace, G. M., and Todd, C. R. (2000). Making consistent IUCN classifications under uncertainty. Conserv. Biol. 14, 1001-1013. doi: 10.1046/j.1523-1739.2000.99125.x

Broderick, M., Hull, S., Therivel, R., Piper, J., Masden, E., Denwood, M., et al. (2013). Cumulative Impact Assessment Guidelines: Guiding Principles for Cumulative Impacts Assessment in Offshore Wind Farms. London: RenewableUK.

Devine-Wright, P. (2005). Beyond NIMBYism: towards an integrated framework for understanding public perceptions of wind energy. Wind Energy 8, 125-139. doi: $10.1002 /$ we. 124

Fox, A., Desholm, M., Kahlert, J., Christensen, T. K., and Petersen, I. K. (2006). Information needs to support environmental impact assessment of the effects of European marine offshore wind farms on birds. Ibis 148, 129-144. doi: 10.1111/j.1474-919X.2006.00510.x

Furness, R. W., Wade, H. M., and Masden, E. A. (2013). Assessing vulnerability of marine bird populations to offshore wind farms. J. Environ. Manag. 119, 56-66. doi: 10.1016/j.jenvman.2013.01.025

Furness, R. W., Wade, H. M., Robbins, A. M., and Masden, E. A. (2012). Assessing the sensitivity of seabird populations to adverse effects from tidal stream turbines and wave energy devices. ICES J. Mar. Sci. 69, 1466-1479. doi: 10.1093/icesjms/fss131

Garthe, S., and Hüppop, O. (2004). Scaling possible adverse effects of marine wind farms on seabirds: developing and applying a vulnerability index. J. Appl. Ecol. 41, 724-734. doi: 10.1111/j.0021-8901.2004.00918.x

Greaves, D., Conley, D., Leeney, R. H., Godley, B., Simas, T., Olivares, C. H., et al. (2011). The SOWFIA Project: Streamlining of Ocean Wave Farms Impact Assessment. Plymouth: University of Plymouth. 
Grecian, W. J., Inger, R., Attrill, M. J., Bearhop, S., Godley, B. J., Witt, M. J., et al. (2010). Potential impacts of wave-powered marine renewable energy installations on marine birds. Ibis 152, 683-697. doi: 10.1111/j.1474919X.2010.01048.x

Halpern, B. S., Walbridge, S., Selkoe, K. A., Kappel, C. V., Micheli, F., D’Agrosa, C., et al. (2008). A global map of human impact on marine ecosystems. Science 319, 948-952. doi: 10.1126/science.1149345

Harwood, J., King, S., Schick, R., Donavan, C., and Booth, C. (2014). A Protocol for Implementing the Interim Population Consequences of Disturbance (PCOD) Approach: Quantifying and Assessing the Effects of UK Offshore Renweable Energy Developments on Marine Mammal Populations. Edinburgh: The Scottish Government.

IEEM., (2010). Guidelines for Ecological Impact Assessment in Britain and Ireland. Winchester: Institution of Ecology and Environmental Management.

Inger, R., Attrill, M. J., Bearhop, S., Broderick, A. C., Grecian, W. J., Hodgson, D. J., et al. (2009). Marine renewable energy: potential benefits to biodiversity? An urgent call for research. J. Appl. Ecol. 46, 1145-1153.

Keenan, G., Sparling, C., Williams, H., and Fortune, F. (2011). SeaGen Environmental Monitoring Programme. Report Commisioned by Marine Current Turbines, Bristol.

King, S., Maclean, I. M. D., Norman, T., and Prior, A. (2009). Developing Guidance on Ornithological Cumulative Impact Assessment for Offshore Wind Farm Developers. Report Commisioned by Cowrie, The Crown Estate, London.

Kuhn, T. S., (1970). The Structure of Scientific Revolutions. Chigaco, IL: University of Chicago Press.

Lawrence, D. P., (2007). Impact significance determination-back to basics. Environ. Impact Assess. 27, 755-769. doi: 10.1016/j.eiar.2007.02.011

Leopold, L. B., (1971). A Procedure for Evaluating Environmental Impact. Washington, DC: U.S. Department of the Interior.

Lusseau, D., Christiansen, F., Harwood, J., Mendes, S., Thompson, P. M., Smith, K., et al. (2012). Assessing the Risks to Marine Mammal Populations from Renewable Energy Devices - an Interim Approach. NERC MREKE Workshop Report. Available online at: https://ke.services.nerc.ac.uk/Marine/Members/ Pages/KEproposals.aspx

Maclean, I. M. D., and Rehfisch, M. M. (2008). Developing Guidelines for Ornithological Cumulative Impact Assessment: Draft Discussion Document. Report Commisioned by Cowrie, British Trust for Ornithology, Thetford.

Maclean, I. M. D., Rehfisch, M. M., Skov, H., and Thaxter, C. B. (2013). Evaluating the statistical power of detecting changes in the abundance of seabirds at sea. Ibis 155, 113-126. doi: 10.1111/j.1474-919X.2012.01272.x

Maclean, I. M. D., Wright, L., Showler, D., and Rehfisch, M. M. (2009). A Review of Assessment Methodologies for Offshore Wind Farms. Report Commisioned by Cowrie, British Trust for Ornithology, Thetford.

Macleod, K., Lacey, C., Quick, N., Hastie, G., and Wilson, J. (2011). Guidance on Survey and Monitoring in Relation to Marine Renewables Deployments in
Scotland. Vol. 2. Cetaceans and Basking Sharks. Draft report to Scottish Natural Heritage and Marine Scotland (Inverness).

Masden, E. A., Fox, A. D., Furness, R. W., Bullman, R., and Haydon, D. T. (2010). Cumulative impact assessments and bird/wind farm interactions: developing a conceptual framework. Environ. Impact Assess. 30, 1-7. doi: 10.1016/j.eiar.2009.05.002

Mitchell, P. I., Newton, S. F., Ratcliffe, N., and Dunn, T. E. (2004). Seabird Populations of Britain and Ireland. London: Poyser.

Percival, S., Band, B., and Leeming, T. (1999). "Assessing the ornithological effects of wind farms: developing a standard methodology," in Proceedings of the 21st British Wind Energy Association Conference (Cambridge).

SNH. (2013). Environmental Assessment Handbook: Guidance on the Environmental Impact Assessment Process. Edinburgh: Scottish Natural Heritage.

Taylor, B. L., Martinez, M., Gerrodette, T., Barlow, J., and Hrovat, Y. N. (2006). Lessons from monitoring trends in abundance of marine mammals. Mar. Mammal. Sci. 23, 157-175. doi: 10.1111/j.1748-7692.2006. 00092.x

Tyler-Walters, H., Hiscock, K., Lear, D., and Jackson, A. (2001). Identifying Species and Ecosystem Sensitivities. Report Commisioned by Defra, The Marine Life Information Network (MarLIN), Plymouth.

Wood, G. (2008). Thresholds and criteria for evaluating and communicating impact significance in environmental statements:'see no evil, hear no evil, speak no evil'? Environ. Impact Assess. Rev. 28, 22-38. doi: 10.1016/j.eiar.2007.03.003

Conflict of Interest Statement: The authors declare that the research was conducted in the absence of any commercial or financial relationships that could be construed as a potential conflict of interest.

Received: 08 November 2014; paper pending published: 11 November 2014; accepted: 25 November 2014; published online: 16 December 2014.

Citation: Maclean IMD, Inger R, Benson D, Booth CG, Embling CB, Grecian WJ, Heymans JJ, Plummer KE, Shackshaft M, Sparling CE, Wilson B, Wright LJ, Bradbury G, Christen N, Godley BJ, Jackson AC, McCluskie A, Nicholls-Lee R and Bearhop S (2014) Resolving issues with environmental impact assessment of marine renewable energy installations. Front. Mar. Sci. 1:75. doi: 10.3389/fmars.2014.00075

This article was submitted to Marine Affairs and Policy, a section of the journal Frontiers in Marine Science.

Copyright (c) 2014 Maclean, Inger, Benson, Booth, Embling, Grecian, Heymans, Plummer, Shackshaft, Sparling, Wilson, Wright, Bradbury, Christen, Godley, Jackson, McCluskie, Nicholls-Lee and Bearhop. This is an open-access article distributed under the terms of the Creative Commons Attribution License (CC BY). The use, distribution or reproduction in other forums is permitted, provided the original author(s) or licensor are credited and that the original publication in this journal is cited, in accordance with accepted academic practice. No use, distribution or reproduction is permitted which does not comply with these terms. 